\title{
Liquid-phase Infiltration of Thermal Sintered Skeletons by Low-temperature Gold Eutectic Alloys
}

\author{
M. Lanzetta \\ Department of Mechanical, Nuclear and Production Engineering \\ University of Pisa, Italy \\ submitted by M. Santochi (1)
}

\begin{abstract}
The flexibility of powder-based Rapid Prototyping (or Solid Free Form Fabrication) techniques and the densification method described in this paper would open a whole new range of applications where thermal constraints exist. This work examines the infiltration of sintered skeletons made of pure gold spherical powder ranging between 5 and $40 \mu \mathrm{m}$ in size, by binary gold eutectics based on silicon, germanium and tin, with a melting point as low as $278^{\circ} \mathrm{C}$. Experiments have shown that high densification rate, good surface finish and improved mechanical properties can be achieved with this process. The material properties influencing the process performance are pointed out.
\end{abstract}

Keywords:

Powder, Sintering, Infiltration

\section{INTRODUCTION}

The ability to directly fabricate metal parts characterized by high thermal and electrical conductivity, high corrosion resistance, and good strength below $300^{\circ} \mathrm{C}$ would create tremendous opportunities in many application fields. This result can be achieved by combination of a powder processing method like Solid Freeform Fabrication (SFF) or Rapid Prototyping (RP) [1] [2] [3] and densification to full density by capillary infiltration. Green parts of desired shape and complexity (the skeleton) can be directly made from a CAD model by RP.

In addition to RP processes still are under study aiming to reduce porosity [4] [5] [6], current densification methods include:

- $\quad$ sintering to full density, which generally requires a higher temperature than infiltration and may lead to distortions because of shrinkage (linear shrinkage ranges between 15 and $20 \%$, depending on the initial packing);

- infiltration of a metal powder skeleton by a lower melting point metal (usually bronze) or polymers [7]. In addition to a limited material choice, parts are heterogeneous;

- Transient Liquid-phase Infiltration (TLI), capillary induced infiltration of the powder skeleton using an infiltrant similar to the powder material containing a melting point depressant, usually some common alloying element. This technique facilitates homogenization after the liquid metal fills the void space;

This work is derived from current research on TLI [8, 9], which has shown the benefits and drawbacks of element diffusion between phases, and on Three Dimensional Printing [10] [11] [12] [13] [14] [15] [16] initiated at MIT.

The beneficial properties of eutectics are well known, but only a few literature can be found on infiltration by eutectic alloys, particularly regarding gold [13].

The process described in Figure 1 is based on capillary infiltration of the skeleton made of a pure base material by an infiltrant alloy with the composition of a lowtemperature eutectic [14]. Based on that experimentation, this paper will discuss the performance of the infiltration method proposed.

\section{PROCESS APPLICATION}

The intended target use is post-processing of powder skeletons made by 3DPrinting [10] [11] [12] [15] in order to achieve full density. Other metal powder processing methods, including rapid prototyping, tooling and manufacturing [1] [2] [3], are also suitable.

Material systems based on gold powder have not yet been investigated in 3DPrinting, but good performance are expected with size distributions ranging from 10 to 40 $\mu \mathrm{m}$, for previous favorable experience with various metal powders [15]
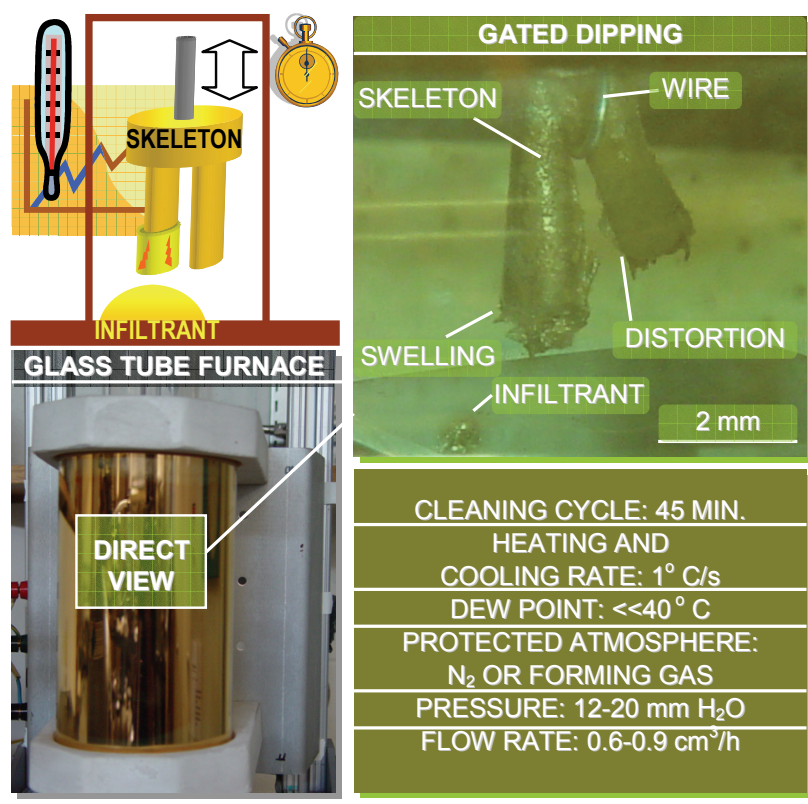

Figure 1: Experimental apparatus and data. A deformed skeleton suspended after infiltration by AuSn at $450^{\circ} \mathrm{C}$ for $120 \mathrm{~s}$. 
The advantage of infiltration by gold eutectics is their lower melting point, in addition to high thermal and electrical conductivity, high corrosion and acid resistance, good strength and biocompatibility.

Jewelry is a potential application because with RP, the designer has complete freedom. Other applications for gold parts are biomedical and dental and MEMS, also on silicon wafer. To completely build parts by a lowtemperature process, sintering can be replaced by lowtemperature skeleton preparation methods, like [16].

\section{PROCESS DESCRIPTION}

The infiltration of a molten metal into a metal powder matrix is driven by capillary force, which mainly depends on the relative surface tension between infiltrant and powder surface and on the skeleton voids size [7] [8]

This relative surface tension also depends on the powder surface type (surface texture, presence of oxides, thermal treatments, etc.) and is a direct consequence of the powder production and of the skeleton processing methods. The powder, skeleton and infiltrant history also influence properties like the alloy composition and the microstructure. Other relevant properties of the molten infiltrant are its viscosity and solidification rate.

The mentioned skeleton, infiltrant and interface properties influence the chemical diffusion of alloying elements from the infiltrant into the skeleton powder grains and vice versa, thus varying their respective composition, microstructure and state.

Solubility, diffusivity and most other material properties are function of each skeleton/infiltrant material pair. In addition, they are temperature dependent (usually with positive correlation). For these reasons, the liquid-phase infiltration process is highly dynamic, because the infiltrant properties are influenced by the changes of the skeleton material properties, and inversely.

\section{INFILTRANT SELECTION}

A major process parameter is the infiltrant composition. The eutectic selection took into account the following criteria:

(1) The category of eutectic alloys was limited to binary metals and metalloids.

(2) Alloys with very-low $\left(<400^{\circ} \mathrm{C}\right)$ eutectic temperatures were selected.

(3) There would have to be a large difference between the eutectic temperature and the melting point of either of the binary components. With the selected AuSi, AuGe and AuSn alloys, this difference is $700-$ $800^{\circ} \mathrm{C}$.

(4) The eutectic temperature of the infilitrant would have to be lower than the sintering temperature of the base

Table 1: Basic properties of the eutectic Infiltrant Alloys (IA) tested from handbooks. MPD = Melting Point Depressant (Si, Ge and $\mathrm{Sn}$ ).

\begin{tabular}{llllll}
\hline IA & $\begin{array}{l}\text { Eutectic } \\
\text { tem- } \\
\text { perature } \\
{\left[{ }^{\circ} \mathrm{C}\right]}\end{array}$ & $\begin{array}{l}\text { Weight } \\
{[\%]}\end{array}$ & $\begin{array}{l}\text { MPD } \\
\text { solu- } \\
\text { bility in } \\
\text { Au [\%] }\end{array}$ & $\begin{array}{l}\text { MPD } \\
\text { density } \\
{\left[\mathrm{g} / \mathrm{cm}^{3}\right]}\end{array}$ & $\begin{array}{l}\text { IA } \\
\text { density } \\
{\left[\mathrm{g} / \mathrm{cm}^{3}\right]}\end{array}$ \\
\hline $\begin{array}{l}\mathrm{Au} \\
\mathrm{Si}\end{array}$ & 361 & 3.16 & $<<1$ & 2.33 & 18.76 \\
$\mathrm{Au}$ & 363 & 12.5 & $<1$ & 5.32 & 17.55 \\
$\mathrm{Ge}$ & & & & & \\
$\mathrm{Au}$ & 278 & 20 & $<4.5$ & 7.3 & 16.9 \\
$\mathrm{Sn}$ & & & & & \\
\hline
\end{tabular}
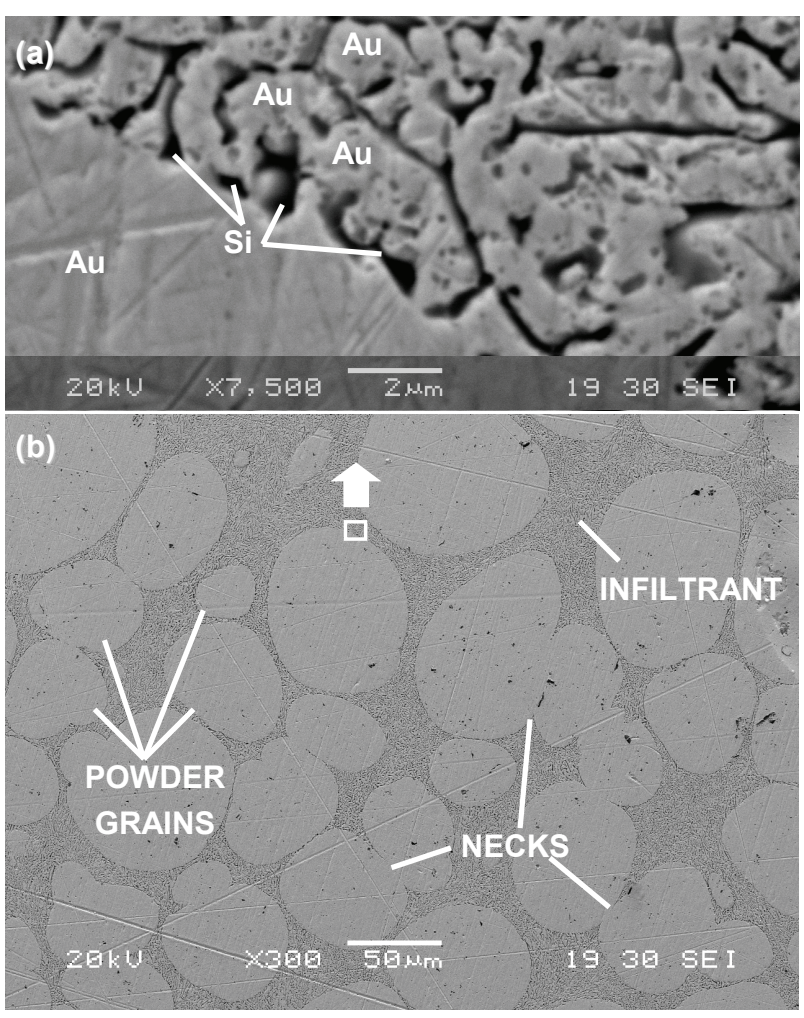

Figure 2: Cross section of a large powder skeleton infiltrated by the AuSi eutectic (b). Detail of the two-phase infiltrant, substantiated by EDS analysis (a).

powder.

With Si-based infiltrant, the final composition can be very close to $99 \%$ depending on the initial packing, corresponding up to 24 karats, because of the low percentage of $\mathrm{Si}$ in the eutectic.

Gold-tin eutectic solder (20 wt. \% Sn), because of its excellent mechanical and thermal properties, is utilized for flip chip and laser bonding in optoelectronic applications.

\section{EXPERIMENTAL TESTS}

The process variables tested and discussed below are:

- skeleton powder size distribution;

- infiltrant material;

- infiltration temperature and time.

U-shaped gold skeletons made by two connected cylinders sized $\varnothing 1.6 \mathrm{~mm}$ by 5 to $10 \mathrm{~mm}$ length have been dipped into the infiltrant in protected atmosphere (Figure 1). Contact occurs at one end, after reaching the melting temperature to prevent premature interaction (gated dipping) and allows penetrating the infiltrant oxide layer, if present.

Skeletons have been made with combinations of $99.99 \%$ pure spherical gold powders [17] obtained by atomization and chemical precipitation, respectively with mesh 83 to $325(30 \mu \mathrm{m}$ average) and from 5 to $10 \mu \mathrm{m}(8.5 \mu \mathrm{m}$ average) alone and in the proportions of $2: 1$ and $1: 1$. Bimodal powder distribution has been selected to improve the packing density and to reduce the sintering temperature. Sintering time was 1 hour at $1000^{\circ} \mathrm{C}$ for the large and $850^{\circ} \mathrm{C}$ for the small and bimodal powders. The melting point of gold is $1064.43^{\circ} \mathrm{C}$. The resulting shrinkage was 2-3\% (linear). A density around $50-70 \%$ was estimated by the geometry and weight of parts.

Gold skeletons have been infiltrated by binary gold eutectics with the properties summarized in Table 1. 


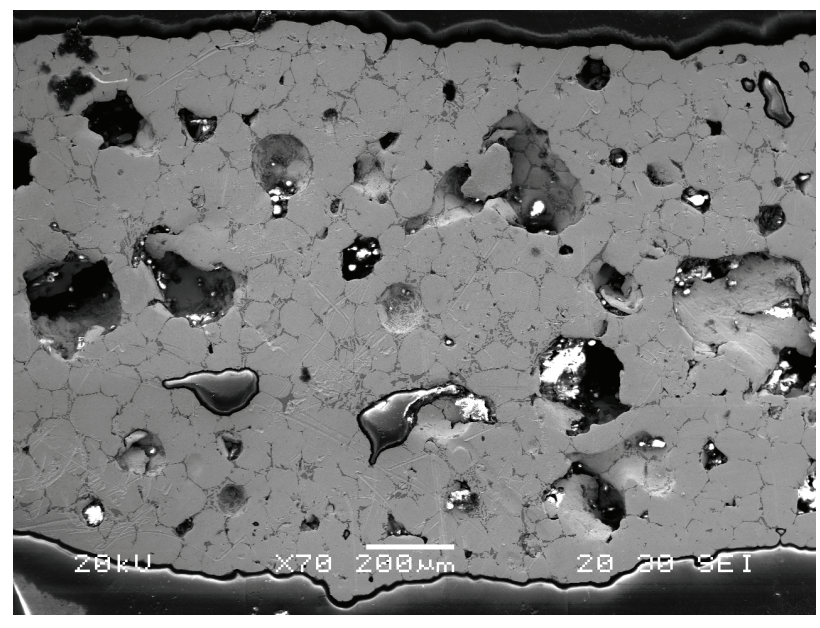

Figure 3: Cross section of a large powder skeleton infiltrated by the AuGe eutectic, with large porosity and the two phases substantiated by EDS analysis.

Infiltration has been directly observed through a special glass tube furnace (Figure 1). The infiltrant rise was clearly visible for its reflectivity, emerging among grains from the inside and in some case even coating the skeleton surface.

In this set of experiments the main target was to achieve a rapid and complete infiltration, so the furnace temperature was progressively raised until a visible infiltration was observed. The infiltration time was a direct consequence of the infiltration speed.

\section{RESULTS}

More than twenty infiltration tests have been completed.

The examined AuSi, AuGe and AuSn eutectics seem good candidates for infiltration to full density of pure gold skeletons. Figure 2 shows an example of a full dense part obtained.

Gold can be wet by its Si-, Ge- and Sn- eutectics. Fine features, like in Figure 4.b, have also been infiltrated. Figure 1 and Figure 4.a (above the erosion level) show the infiltrant coating the external surface of skeletons and the smooth surface achieved, which represents a useful complement to powder processing based methods.

Table 2 reports the temperature and time range of fifteen successful experiments. It can be noticed that a relatively quick infiltration occurs within $100^{\circ} \mathrm{C}$ above the eutectic temperature. Over $200^{\circ} \mathrm{C}$ above the eutectic temperature, the quality of parts generally starts decreasing.

Regarding the microstructure of samples, as predicted from phase diagrams and as shown by etching and Energy Dispersive X-ray Spectrometer (EDS) analysis, for the low solubility of $\mathrm{Si}$ and $\mathrm{Ge}$ in gold (Table 1), two

Table 2: Summary of analyses on infiltrated samples.

\begin{tabular}{|c|c|c|c|c|c|c|}
\hline 를 & 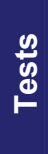 & $\begin{array}{l}\text { Phenomena } \\
\text { observed due } \\
\text { to infiltration }\end{array}$ & $\begin{array}{l}\text { Tem- } \\
\text { perature } \\
\text { range } \\
{\left[{ }^{\circ} \mathrm{C}\right]}\end{array}$ & $\begin{array}{l}\text { Time } \\
\text { range } \\
\text { [min.] }\end{array}$ & $\begin{array}{l}\text { Micro- } \\
\text { hard- } \\
\text { ness } \\
\text { HV }\end{array}$ & 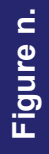 \\
\hline $\begin{array}{l}\mathrm{Au} \\
\mathrm{Si}\end{array}$ & 6 & Small porosity & $400-470$ & $1-5$ & $80-100$ & 2 \\
\hline $\begin{array}{l}\mathrm{Au} \\
\mathrm{Ge}\end{array}$ & 3 & \multirow{2}{*}{$\begin{array}{l}\text { Thermal } \\
\text { softening } \\
\text { Poor wetting }\end{array}$} & $390-420$ & $0.5-2.5$ & $80-100$ & 3 \\
\hline \multirow{2}{*}{$\begin{array}{l}\mathrm{Au} \\
\mathrm{Sn}\end{array}$} & \multirow{2}{*}{6} & & \multirow{2}{*}{$360-500$} & \multirow{2}{*}{$2-20$} & \multirow{2}{*}{$90-140$} & \\
\hline & & Homogenization & & & & \\
\hline
\end{tabular}

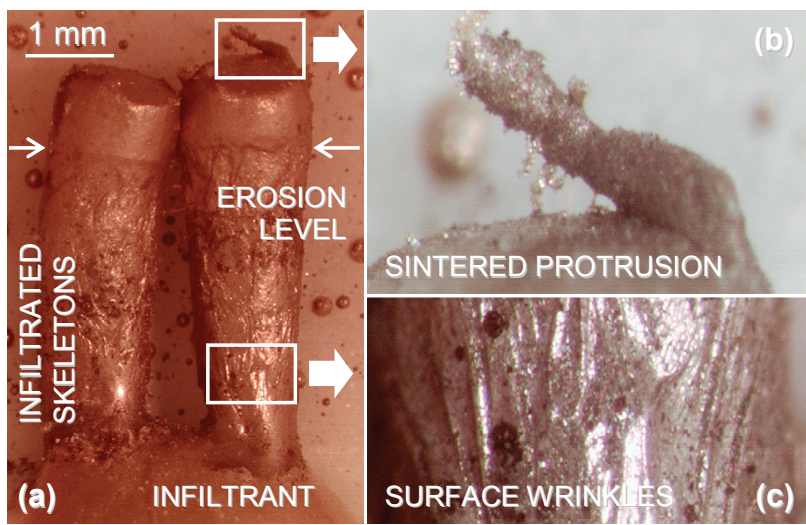

Figure 4: Two pure gold powder skeletons (average size

$10 \mu \mathrm{m}$ ) fully infiltrated by a gold silicon eutectic (a). A small sintered protrusion is also infiltrated (b). Erosion by diffusion of Au into the infiltrant and surface wrinkles (c).

infiltrant phases are present (Figure 2.a and Figure 3), and three in the case of $\mathrm{Sn}$ ( $\xi$ and $\delta$ ). The higher solubility of Sn (Table 1) allows some homogenization also shown by EDS analysis.

On the contrary of standard infiltration, the infiltrants used have better mechanical properties than the base material, so the diffusion of the melting point depressant into the skeleton is favorable. However, the low diffusivity of $\mathrm{Si}$ and $\mathrm{Ge}$ in gold, does not allow improving significantly the limited mechanical properties of pure gold (50-60 HV). As an indicator, the infiltrant Vickers micro-hardness is reported in Table 2. The variability depends on the different phases present. As expected, AuSn infiltrated samples have higher values.

For applications where the aesthetic appearance matters, selecting the infiltrant allows great flexibility. AuS infiltrated parts are brighter yellow than pure gold. Those with AuGe have a red gold color, although AuGe is brownish. The AuSn eutectic is silver as the final color of AuSn infiltrated parts.

From the direct observation of infiltration experiments and the analyses on samples, several phenomena have been listed in Table 2. From their interpretation and by extrapolation from similar processes, like standard infiltration and TLI, the dominating material properties influencing the product quality will be inferred.

Small pores have been found in most samples and may be due to close porosity or to insufficient capillary infiltration or freeze off [8] [9], if present. Freeze off is caused by diffusional solidification of the infiltrant, resulting into early choke-off of the infiltrant supply.

By sectioning the AuGe and AuSn samples, high magnitude porosity has been observed, with holes as large as $200 \mu \mathrm{m}$, which is about two orders of magnitude larger than the initial skeleton porosity. Figure 3 shows large porosity caused by thermal softening. Ge, the melting point depressant in the infiltrant alloy, diffused from the molten infiltrant into the necks among powder grains created during sintering and weakened the skeleton structure. Not only grains have been pulled apart, but the skeleton matrix has also been rearranged in order to minimize the surface energy of the molten metal, with the creation of large almost regular bubbles.

The macroscopic effects of thermal softening are: skeleton distortion (Figure 1) and the swelling of parts caused by the inside porosity.

Poor infiltrant wetting was solved by increasing the temperature. 


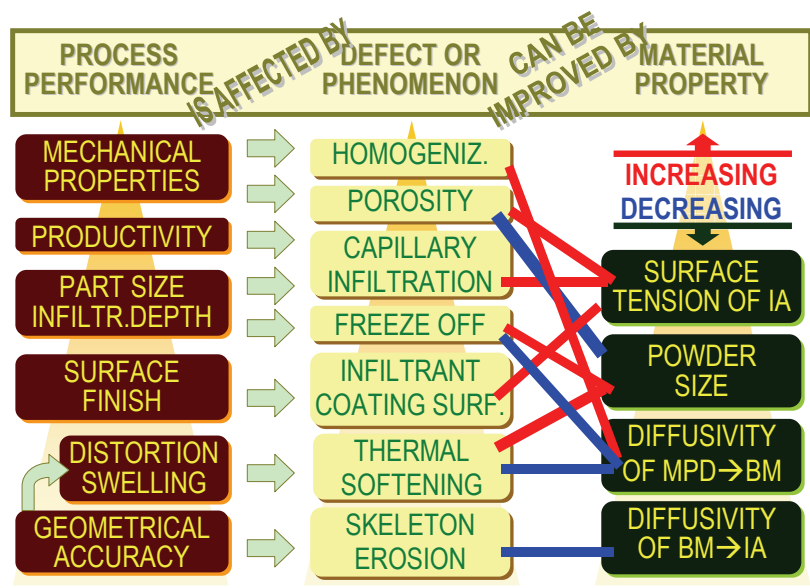

Figure 5: Relationship between product quality and properties of the material system selected, and their negative or positive correlation with the phenomena observed. MPD = Melting Point Depressant. BM = Base Material. IA = Infiltrant Alloy.

Erosion, a typical defect in standard infiltration and TLI, which did not occur in the set of experiments included in Table 2 for their short duration, has been artificially produced (Figure 4), by extending the infiltration time to two hours at $400^{\circ} \mathrm{C}$. Wrinkles show the migration of $\mathrm{Au}$ from the skeleton into the molten infiltrant pool at the bottom.

\section{CONCLUSIONS}

Infiltration of a powder matrix by a eutectic alloy of the base material seems a good candidate for lowtemperature manufacturing of dense parts. An overview of phenomenology was given.

Figure 5 translates the metallurgical aspects discussed above, into production requirements. The positive and negative correlation with the material properties are also indicated. Figure 5 can be used as guide map for defect debugging and process optimization. For example, recalling the dependence on temperature and time, the surface tension tends to increase with the temperature, which is favorable. Increasing also the infiltration time increases diffusion. This is beneficial for homogenization, but it is detrimental for thermal softening and erosion.

The effect of the process parameters outlined in Figure 5 can be investigated in new material systems, like more (not only binary, gold) eutectic alloys with other compatible metals skeletons or different combinations of other base materials with their eutectic alloys and in higher scale experiments to understand the maximum distance traveled by the infiltrant driven by capillary forces at different temperatures.

\section{ACKNOWLEDGMENTS}

The author would like to thank prof. E. Sachs (3DPrinting Lab at MIT) for proposing this topic and supporting experiments. J. Serdy, A. Lorenz and B. Kernan are gratefully acknowledged for their useful suggestions.

Prof. M. Santochi's invaluable advice is acknowledged. SEM micrographs and analyses were taken with Mr. P. Narducci - Dept. Chem. Eng., Pisa Univ.

\section{REFERENCES}

[1] Kruth, J.P., 1991, Material Incress Manufacturing by
Rapid Prototyping Techniques, Annals of the CIRP, 40/2:603-614

[2] Kruth, J.P., Leu, M.C., $\quad$ Nakagawa, T., 1998 , Progress in Additive Manufacturing and Rapid Prototyping, Annals of the CIRP, 47/2:525-540.

[3] Levy, G.N., Schindel, R., Kruth, J.P., 2003, Rapid manufacturing and rapid tooling with layer manufacturing (LM) technologies, state of the art and future perspectives, Annals of the CIRP, 52/2:589-609.

[4] Kruth, J.-P., Van der Schueren, B., Bonse, J.E., Morren, B., 1996, Basic Powder Metallurgical Aspects in Selective Metal Powder Sintering, Annals of the CIRP, 45/1:183-186.

[5] O'Neill, ,W., $\quad$ Sutcliffe, C.J., $\quad$ Morgan, R. Landsborough, A., Hon, K.K.B., 1999, Investigation on Multi-Layer Direct Metal Laser Sintering of $316 \mathrm{~L}$ Stainless Steel Powder Beds, Annals of the CIRP, 48/1:151-154

[6] Kruth, J.P., Froyen, L., Rombouts, M., Van Vaerenbergh, J., Mercelis, P., 2003, New Ferro Powder for Selective Laser Sintering of Dense Parts, Annals of the CIRP, 52/1:139-142.

[7] Evans, R.S., Bourell, D.L., Beaman, J.J., Campbell, M.I., 2005, Rapid manufacturing of silicon carbide composites, Rapid Prototyping Journal, 11/1:37-40.

[8] Lorenz, A., Sachs, E., Allen, S. Rafflenbeul, L., Kernan, B., 2004, Densification of a powder-metal skeleton by transient liquid-phase infiltration, Metallurgical and Materials Transactions A: Physical Metallurgy and Materials Science, 35A/2:631-640.

[9] Lorenz, A., Sachs, E., Allen, S., 2004, Freeze-off limits in transient liquid-phase infiltration, Metallurgical and Materials Transactions A: Physical Metallurgy and Materials Science, 35A/2:641-653.

[10] Sachs, E., Cima, M., Cornie, J., Brancazio, D., Bredt, J., $\quad$ Curodeau, A., Fan, T., Khanuja, S., Lauder, A., Lee, J., Michaels, S., 1993, Threedimensional printing: the physics and implications of additive manufacturing, Annals of the CIRP, 42/1:257-260.

[11] Sachs, E., Haggerty, J., Cima, M., Williams, P., 1993, Three dimensional Printing Techniques, US Patent \# 5,204,055 04/28/1993.

[12] Sachs, E., Curodeau, A., Fan, T., Bredt, J.F., Cima, M., Brancazio, D., 2000, Three dimensional printing methods, US Patent \# 6,146,567.

[13] Buttz, D., 2001, Materials Systems for Low Shrinkage Metal Skeletons in Three Dimensional Printing, MEng Thesis, Massachusetts Institute of Technology.

[14] Lanzetta, M., Sachs, E., 2003, Low-Temperature Processing of Metal Macro and Microparts, Proc. $6^{\text {th }}$ Aitem Conf., Ed. L. Carrino, Gaeta, Italy, Sep.8-10, 2003:552-565.

[15] Lanzetta, M., Sachs, E., 2001, Development of a Semiautomatic Machine for the Drop On Demand Three Dimensional Printing, Proc. $5^{\text {th }}$ Aitem Conf., Ed. L. Galantucci, Bari, Italy, Sep.18-20, 2001:129-144.

[16] Sachs, E.M., Hadjiloucas, C., Allen, S., Yoo, H.J., 2003, Metal and ceramic containing parts produced from powder using binders derived from salt, US Patent \# 6,508,980.

[17] Technic, Inc., Providence, RI, USA. 